\title{
Principais Técnicas de Fisioterapia Respiratória em Pediatria
}

\author{
Mônica Sanchez Stopiglia1; Maria Regina de Carvalho Coppo²
}

\section{Resumo}

As técnicas de fisioterapia respiratória utilizadas em recém-nascidos e lactentes, que estão em constante crescimento e desenvolvimento, diferem de forma substancial das práticas utilizadas no adulto, devendo respeitar a idade do paciente e fatores anatômicos e fisiológicos relativos; doença pulmonar e doenças associadas; condições clínicas e evolução do quadro; cooperação e aderência ao tratamento; e crescimento e desenvolvimento neuropsicomotor. São descritas técnicas de fisioterapia respiratória para desobstrução de vias aéreas superiores e inferiores.

Palavras chave: fisioterapia respiratória, neonatologia, pediatria

Stopiglia, Mônica Sanchez; Coppo, Maria Regina de Carvalho. "Principais Técnicas de Fisioterapia Respiratória em Pediatria", in Anais do 20. Congresso Internacional Sabará de Especialidades Pediátricas

\footnotetext{
${ }^{1}$ Fisioterapeuta Mestre em Neurociências pelo Departamento de Neurologia da Faculdade de Ciências Médicas da UNICAMP

Responsável pela área de Fisioterapia Neonatal do Hospital da Mulher Prof. Dr. José Aristodemo Pinotti - CAISM-UNICAMP Responsável pelo Serviço de Fisioterapia da Maternidade de Campinas

${ }^{2}$ Fisioterapeuta Mestre em Saúde da Criança e do Adolescente pelo Centro de Investigações Pediátricas da UNICAMP

Responsável pelo Setor de Fisioterapia do Hospital da Mulher Prof. Dr. José Aristodemo Pinotti - CAISM-UNICAMP
} 


\section{Principais Técnicas de Fisioterapia Respiratória em Pediatria}

Fisioterapia respiratória é um processo dinâmico que deve ser visto como uma aplicação terapêtica de intervenções mecânicas, baseadas na fisiologia das vias aéreas. Faz parte de seus objetivos a prevenção ou a redução das consequências da obstrução por secreção, tais como hiperinsuflação, atelectasia, má distribuição da ventilação, alteração da relação ventilação/perfusão (V/Q) e aumento do trabalho respiratório. Secundariamente, a remoção de secreções infectadas, de mediadores inflamatórios e a consequente redução da atividade proteolítica e oxidativa das vias aéreas, pode prevenir ou reduzir as lesões teciduais provocadas pelas infecções broncopulmonares. (OBERWALDNER, 2000; GÜRSLI, 2002; POSTIAUX, 2000)

No que diz respeito à faixa etária neonatal e pediátrica, onde os pacientes estão em constante crescimento e desenvolvimento, a abordagem fisioterapêutica difere de forma substancial das práticas utilizadas no adulto, devendo respeitar a idade do paciente e fatores anatômicos e fisiológicos relativos; doença pulmonar e doenças associadas; condições clínicas e evolução do quadro; cooperação e aderência ao tratamento; e crescimento e desenvolvimento neuropsicomotor.

Em pediatria, a aplicação das técnicas varia entre as formas passiva, ativo-assistida ou ativa, de acordo com a idade e o grau de cooperação do paciente.

\section{Técnicas para remoção de secreções em vias aéreas extratorácicas:}

\subsection{Desobstrução Rinofaríngea Retrógrada - DRR}

A DRR é uma manobra de inspiração forçada que tem por objetivo remover secreções da rinofaringe. Pode ser utilizada com ou sem o uso de instilação local de solução fisiológica. Quando utilizada com instilação, recebe a denominação de DRR+I.

Seu princípio está fundamentado no aumento da velocidade do fluxo aéreo inspiratório que diminui a pressão dos orifícios sinusais e da trompa de Eustáquio (provocando o chamado efeito de Venturi), favorecendo a mobilização das secreções destas cavidades para o conduto rinofaríngeo principal. (POSTIAUX, 2000)

É realizada de forma passiva em lactentes e crianças pequenas, ou ativa em crianças acima de 4-5 anos, adolescentes e adultos. Na forma passiva, o aumento do fluxo é gerado pelo reflexo inspiratório originado após uma expiração completa, provocado pelo choro ou por uma manobra de fisioterapia respiratória [Expiração lenta e prolongada (ELPr), ou 
aumento do fluxo expiratório lento (AFEL)por exemplo]. (POSTIAUX, 2000; FELTRIM, 2001)

Para a aplicação da técnica na forma passiva, a criança deve estar em decúbito dorsal, elevado a aproximadamente $30^{\circ}$. O fisioterapeuta pode posicionar-se de duas formas:

- atrás da maca, com uma das mãos elevando a mandíbula, apoiando os dedos indicador e médio na base da língua, ao final do tempo expiratório, obrigando a criança a inspirar profundamente pelo nariz. (imagem 1)

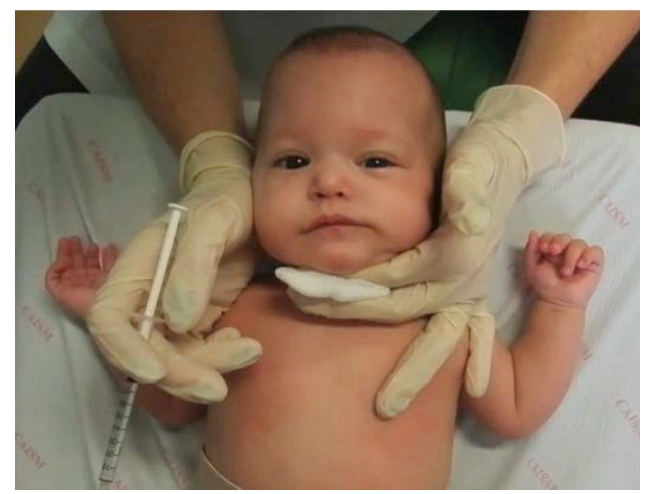

Imagem 1- arquivo do Setor de Fisioterapia - CAISM-UNICAMP

- lateralmente ao leito, ocluindo a boca do paciente com a região hipotenar da mão, fechando rapidamente o orifício bucal. (imagem 2)

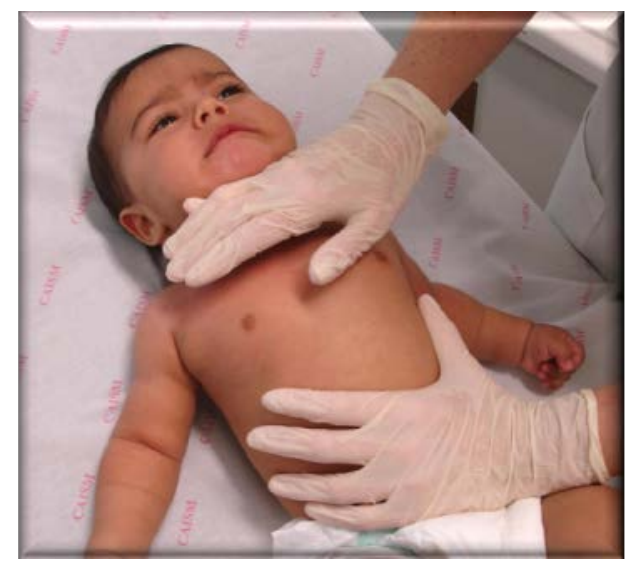

Imagem 2- arquivo do Setor de Fisioterapia - CAISM-UNICAMP

Quando realizada após manobras de AFE ou ELPr, o fisioterapeuta pode utilizar a região hipotenar da mão que acaba de concluir o apoio torácico, ou ainda realizar o movimento com a mão que dava apoio abdominal, fazendo-a sustentar a mandíbula e fechar a boca, forçando uma nasoaspiração.

Esta técnica pode ser realizada de forma isolada, quando somente as VAS estão comprometidas, ou entre as manobras de desobstrução de vias aéreas inferiores (VAI). Pode ainda, ser utilizada como adjuvante na avaliação do paciente, quando a obstrução por 
secreções em vias aéreas superiores dificulta a ausculta pulmonar e a determinação da presença e quantidade de secreções em VAI. (POSTIUAUX, 2000; FELTRIM, 2001; POSTIAUX, 2001; STOPIGLIA, 2007)

Para a realização da DRR+I, instila-se solução de cloreto de sódio a 0,9\% (solução fisiológica) em quantidades variáveis de acordo com a idade e tamanho da criança e o grau de obstrução nasal, ou ainda, substância medicamentosa (por indicação médica).

Em pacientes acima de 4-5 anos, a DRR+I pode ser realizada posicionando a cabeça em ligeira hiperextensão e rodando-a para o lado da narina a ser instilada. Utiliza-se, em geral, $1 / 2 \mathrm{~mL}$ de cloreto de sódio a $0,9 \%$ (solução fisiológica) em cada narina, nesta faixa etária.

Com a cabeça ainda nesta posição, massageia-se ao redor da aleta nasal e sobre a região do seio maxilar por aproximadamente 30 segundos, para que haja tempo do soro instilado penetrar pelo óstio e banhar o seio desta hemiface.

A seguir, a cabeça é virada para o lado oposto, e solicita-se ao paciente que realize a DRR, inspirando profundamente e fazendo vibrar o véu do palato, como se imitasse o "ronco de um porquinho”. Drenadas as secreções desta narina, realizam-se os mesmos passos para o outro lado. Este procedimento pode ser repetido enquanto persistirem as secreções nasais e deve ser ensinado progressivamente à criança, visando sua autonomia. No paciente com idade inferior a 3-4 anos, devido à formação incompleta dos seios da face, não existe a necessidade de rodar a cabeça para a realização da técnica.

\subsection{Glossopulsão retrógrada - GPR}

A GPR é uma técnica passiva utilizada em lactentes ou crianças pequenas, incapazes de expectorar. Tem o objetivo de conduzir as secreções eliminadas pela tosse, do fundo da cavidade bucal até a comissura labial, para que sejam expelidas.

Para a realização da técnica o fisioterapeuta segura, com uma das mãos, a cabeça do paciente, apoiando o polegar sob o maxilar, na base da língua, impedindo a deglutição. Os outros quatro dedos são suavemente apoiados sobre a face lateral do crânio, sustentando a cabeça. Durante o tempo expiratório, o estreitamento do conduto orofaríngeo provocado pelo apoio do polegar, aumenta a velocidade do ar expirado, impulsionando a secreção do fundo da cavidade bucal até a comissura labial. (imagem 3) 


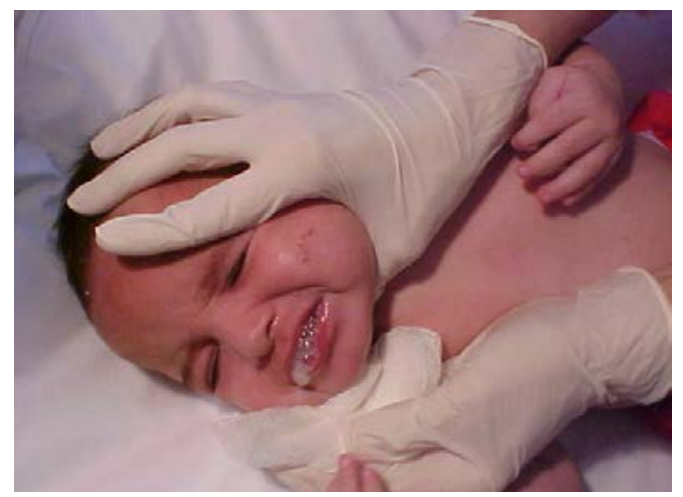

Imagem 3- arquivo do Setor de Fisioterapia - CAISM-UNICAMP

O muco poderá então ser coletado em um lenço de papel ou um recipiente transparente, permitindo um exame macroscópico.

A utilidade prática desta técnica é permitir ao fisioterapeuta uma apreciação da coloração, consistência, qualidades reológicas e a eventual presença de sangue nas secreções coletadas. Por este motivo, deve ser reservada aos casos em que haja necessidade, pois, apesar de eficaz, causa desconforto ao paciente. (POSTIAUX, 2000; FELTRIM, 2001)

\section{Técnicas para remoção de secreções em vias aéreas intratorácicas:}

\subsection{Aumento do Fluxo Expiratório (AFE)}

Esta técnica foi descrita por Barthe, no final da década de 1960, sendo denominada “Aceleração do Fluxo Expiratório” até 1994. Após a Conferência de Consenso de Técnicas Manuais de Fisioterapia Respiratória (Lyon, França, 1995), passou a ser conhecida pela denominação atual.

A AFE é definida como um aumento passivo, ativo-assistido ou ativo do fluxo aéreo expiratório, com o objetivo de mobilizar, carrear e eliminar as secreções traqueobrônquicas, com ou sem a ajuda de um fisioterapeuta.

A AFE, de acordo com o objetivo desejado, pode ser realizada de forma rápida, aumento do fluxo expiratório rápido (AFER), ou de forma lenta, aumento do fluxo expiratório lento (AFEL): (POSTIAUX, 2001; BARTHE, 1990; DELAUNAY, 1998; WILS, 1998; POSTIAUX, 1992; BERNARD-NARBONNE, 2003; COPPO, 2007)

- AFER: tem por objetivo promover a progressão das secreções dos brônquios de médio para os de grande calibre, por meio do aumento do fluxo aéreo expiratório nos primeiros troncos brônquicos e traqueia, a grande velocidade. A técnica assemelha-se a um exercício de expiração forçada não prolongada, próximo ao pico de fluxo, e se aproxima da tosse sem o 
fechamento da glote. Está indicada quando a ausculta pulmonar evidencia secreções nas vias aéreas de grande calibre.

- AFEL: tem por objetivo mobilizar as secreções dos pequenos brônquios até as vias aéreas proximais, por meio de uma expiração lenta e prolongada, gerando baixo fluxo e baixo volume pulmonar, para permitir a eliminação de secreções mais periféricas. Nesta técnica, realiza-se uma expiração longa e não forçada, impondo um fluxo lento e prolongado ao paciente, de forma a conservar a abertura dos brônquios de pequeno calibre e inibir o fechamento precoce dos pontos de igual pressão.

Em função da localização das secreções nas vias aéreas inferiores, pode-se graduar a expiração, tornando a técnica variável em velocidade, fluxo e volume de ar mobilizado; modulável em função do grau e do local da obstrução, da doença, da quantidade e da qualidade das secreções; e adaptável segundo a idade, o grau de compreensão e de atenção do paciente.

\subsubsection{AFE PASSIVA}

A técnica descrita a seguir é denominada Técnica de Referência. (BARTHE, 1990) É direcionada preferencialmente a lactentes, crianças pequenas, ou quando não se consegue cooperação por parte do paciente.

Para a realização da técnica, o fisioterapeuta se posiciona em pé, lateralmente ao paciente, com os cotovelos semi-fletidos, realizando a manobra sem utilizar o peso de seu corpo. A técnica foi descrita originalmente com o paciente posicionado em decúbito dorsal, porém é recomendado elevá-lo a $30^{\circ}$ (postura de segurança), por ser este um posicionamento mais confortável, diminuindo o peso das vísceras sobre o diafragma, facilitando sua excursão e reduzindo o risco de episódios de refluxo gastro-esofágico.

Na Técnica de Referência, uma das mãos é posicionada sobre o tórax e outra sobre o abdome. A mão torácica é colocada entre a fúrcula esternal e a linha intermamária, envolvendo anterior e lateralmente o tórax da criança. A mão deve ser moldada sobre o tórax, mas a superfície de contato varia de acordo com o tamanho da mão do terapeuta e do tórax do paciente.

A mão abdominal posiciona-se sobre o umbigo e as últimas costelas. O polegar e o indicador devem estar em contato com as costelas inferiores, para melhor perceber a medida do ritmo respiratório e "sentir" a criança respirar sob suas mãos. (imagem 4) 


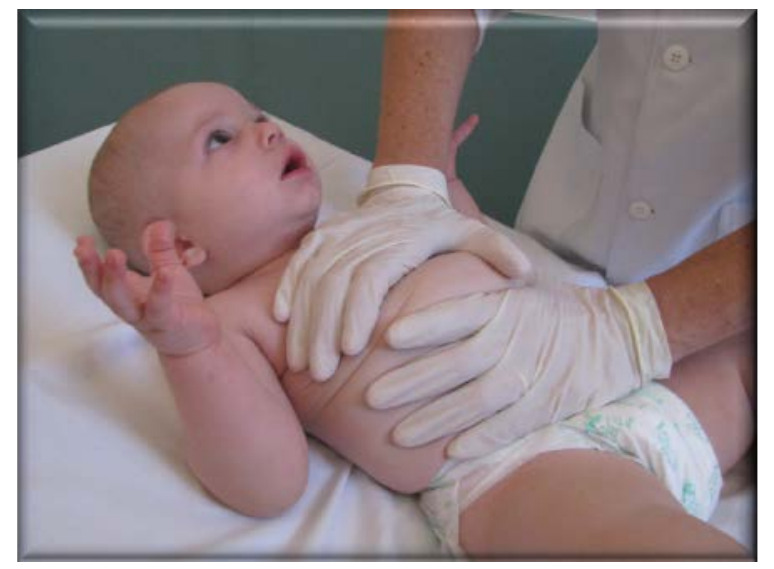

Imagem 4- arquivo do Setor de Fisioterapia - CAISM-UNICAMP

A dinâmica da técnica consiste num movimento obliquo da mão torácica, de cima para baixo e de frente para trás (simultaneamente), acompanhando o movimento expiratório. Já a mão abdominal pode variar de acordo com a idade e a doença do paciente, podendo ser adaptada das seguintes formas:

1 - movendo-se de maneira sincronizada e ativa com a mão torácica, para uma manobra mais intensa. Esta variável está mais indicada para pacientes maiores de 2 anos, quando a maleabilidade e a conformação torácicas já sofreram as alterações fisiológicas próprias da idade. (imagem 5)

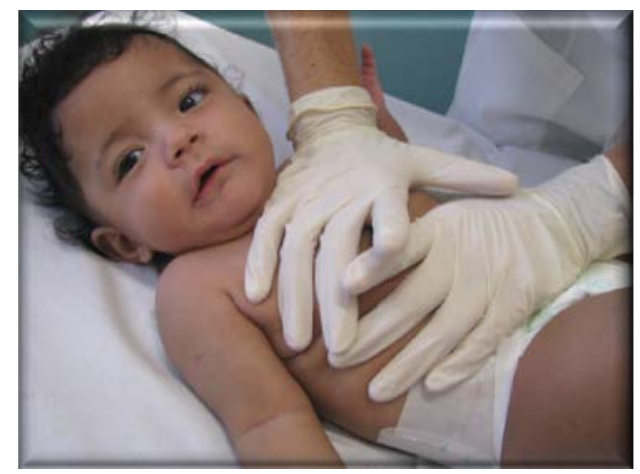

Imagem 5- arquivo do Setor de Fisioterapia - CAISM-UNICAMP

2 - de forma passiva, funcionando como uma cinta abdominal, em contra apoio. Na nossa experiência, utilizamos esta variável preferencialmente em lactentes. (imagem 6)

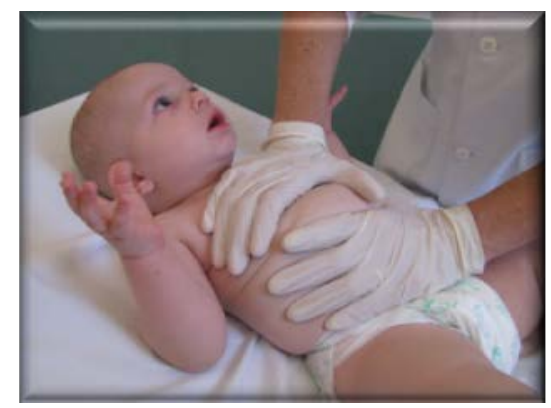


3 - como uma ponte, cujos pilares são o polegar e o indicador (ou dedo médio). Esta variação é denominada “Técnica da Ponte” e tem por objetivo limitar a expansão das últimas costelas, aproximando origem e inserção do diafragma durante a inspiração, melhorando a força de contração. Além disso, preserva o abdome, criando um limite mecânico para a mão torácica, o que previne alterações do fluxo sanguíneo cerebral causadas pelo aumento da pressão intratorácica. É utilizada principalmente em recém-nascidos prematuros, durante o período neonatal. (BARTHE, 1990; DEMONT, 2007; COPPO, 2007) (imagem 7)

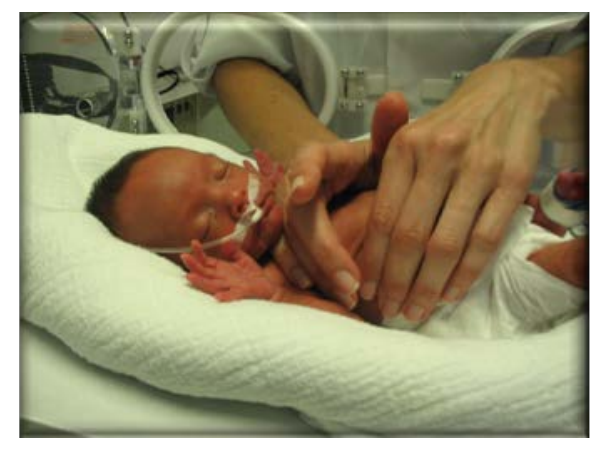

Imagem 7- arquivo do Setor de Fisioterapia - CAISM-UNICAMP

A pressão da manobra é sempre suave, simétrica e a mão nunca deve deslizar sobre a pele, perdendo o contato com o tórax. A pressão/mobilização torácica deve seguir rigorosamente as curvaturas costais, não ultrapassando a fisiologia articular nem os limites de elasticidade costal. Quando associada à mobilização abdominal, promove a eliminação de maior volume de ar, por redução de todos os diâmetros torácicos, proporcionando melhor carreamento e eliminação das secreções traqueobrônquicas. (FELTRIM, 2001, BARTHE, 1990)

A manobra deve começar no platô inspiratório do paciente. A efetividade da técnica é maior quando realizada a partir de um volume inspiratório máximo. Isto é possível após uma expiração prolongada passiva, pois esta provoca uma inspiração reflexa próxima ao volume de reserva inspiratório, aumentando o volume pulmonar. Se a manobra for iniciada antes do término da inspiração, provoca um bloqueio reflexo torácico de defesa que consiste no fechamento da glote, bloqueio da respiração ou ainda ativação da musculatura inspiratória. Por este motivo, em recém-nascidos ou crianças taquipneicas, a manobra pode ser feita a cada dois ou três ciclos respiratórios. Se, por outro lado, for começada após o início da expiração, o volume pulmonar será menor, mobilizando pouca secreção e tornando-a ineficaz. (FELTRIM, 2001; BARTHE, 1990; DELAUNAY, 1998)

O número de manobras é individualizado, e devem ser repetidas até que se perceba a vibração das secreções sob a mão torácica e/ou se escutem as secreções na boca ou no tubo 
endotraqueal. Somente então, se necessário, deve ser estimulada a tosse ou realizada a aspiração.

As manobras de AFE também podem ser associadas à vibração ao final da expiração e/ou DRR. (FELTRIM, 2001; BARTHE, 1990; DELAUNAY, 1998; WILS, 1998)

\subsubsection{AFE ATIVO-ASSISTIDA}

Nos pacientes cooperantes, capazes de compreender a técnica (geralmente acima dos 3 anos de idade), pode-se realizar a AFE ativo-assistida. Para tanto, ensina-se o paciente a expirar com a glote aberta, imitando o som de um “A” expirado. (FELTRIM, 2001; BARTHE, 1990; WILS, 1998)

Em crianças pequenas, exemplos como "aquecer os dedos com o ar que sai da boca", “embaçar o espelho fazendo fumacinha com a boca” ou "fazer bafinho”, ajudam a entender mais facilmente como a expiração deve ser realizada.

O paciente pode estar sentado, semi-sentado ou deitado. Na posição sentada, o terapeuta deve se posicionar atrás do paciente, envolvendo com os braços o tórax do mesmo, de forma que os cotovelos apoiem as costelas lateralmente e as mãos sejam posicionadas sobre o esterno. Como anteparo entre o tórax do terapeuta e o dorso do paciente pode-se utilizar um travesseiro firme ou um lençol dobrado. O fisioterapeuta acompanha a expiração, a partir do platô inspiratório, no mesmo sentido do movimento fisiológico, diminuindo todos os diâmetros torácicos e aumentando o fluxo de ar. (imagens 8 e 9)

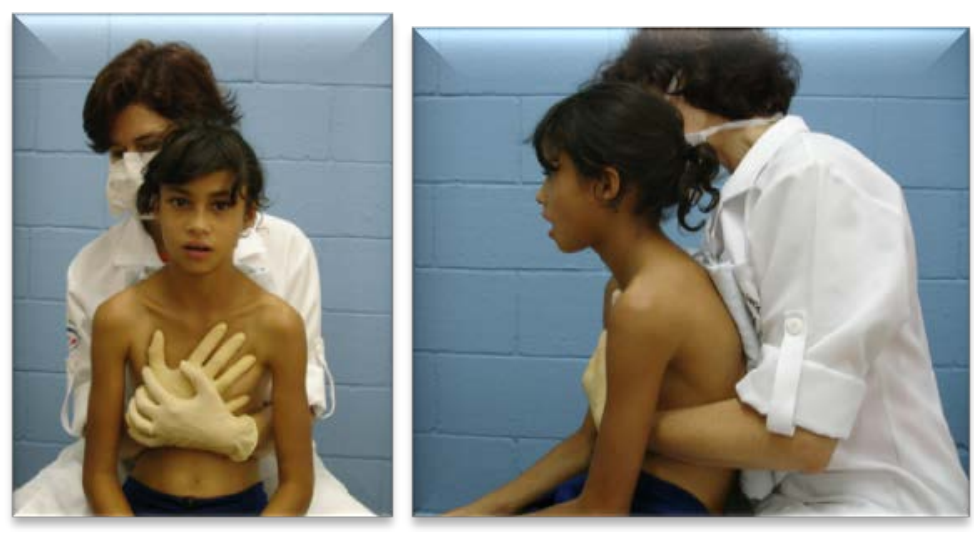

Imagens 8 e 9- arquivo do Setor de Fisioterapia - CAISM-UNICAMP

Manobras de AFER ou AFEL devem ser moduladas durante a terapia, de acordo com a localização das secreções, percebidas através da ausculta pulmonar, palpação das vibrações no tórax e/ou escuta dos sons na boca.

A técnica de AFE está indicada para todas as situações de obstrução brônquica proximal ou distal, causadas por estase de secreções. Os indicadores são os ruídos 
respiratórios, a qualidade das secreções, as vibrações e suas localizações e as sensações do paciente. A escolha do tipo de manobra (AFEL ou AFER) dependerá da análise dos ruídos respiratórios pela ausculta pulmonar. São consideradas contra-indicações absolutas, as situações onde ainda não existe a presença de secreções pulmonares. (FELTRIM, 2001; BARTHE, 1990; WILS, 1998; COPPO, 2007)

Particularmente na AFER, a alta velocidade expiratória pode levar ao colapso das vias aéreas em certas enfermidades como asma, enfisema ou traqueobroncodisplasia, constituindo um limite para a aplicação da técnica. (POSTIAUX, 1992)

Um controle da ausculta pulmonar é sempre necessário para se apurar a eficácia da terapia. O seguimento das terapias se faz a partir de observações qualitativas, quantitativas e colorimétricas das secreções; das variações da frequência respiratória; da diminuição da dispnéia e às vezes da cianose nos casos mais graves; e também de acordo com a radiografia e a ausculta pulmonar.

O número e a duração das sessões variam em função do grau de obstrução, da qualidade das secreções e do estado de fadiga do paciente. (BARTHE, 1990, WILS, 1998)

\subsection{Expiração Lenta e Prolongada (ELPr)}

A ELPr é uma técnica passiva de ajuda expiratória aplicada ao lactente, obtida por meio de pressão manual tóraco-abdominal lenta, com início no final de uma expiração espontânea, prosseguindo até o volume residual. Descrita por Postiaux em 1980, tem como objetivo a desinsuflação pulmonar completa, com consequente depuração da periferia broncopulmonar, obtida por um volume expirado maior que o de uma expiração normal. Este efeito é possível graças ao tempo expiratório prolongado, provocado em um tórax bastante maleável (devido à suas propriedades fisiológicas nesta faixa etária), induzindo a criança a respirar a baixo volume pulmonar (volume de reserva expiratório). (POSTIAUX, 2000; FELTRIM, 2001; BARTHE, 1990)

Para realização da técnica o paciente deve ser posicionado em decúbito dorsal horizontal, ou elevado a $30^{\circ}$, numa superfície semi-rígida. As mãos do terapeuta devem ser colocadas uma sobre o tórax e outra sobre o abdome. A mão torácica deve estar localizada entre a fúrcula esternal e a linha intermamária, com o apoio da mão do terapeuta variando de acordo com o tamanho do tórax do paciente. A mão abdominal posiciona-se sobre o umbigo e as últimas costelas. O fisioterapeuta exerce uma pressão manual tóraco-abdominal, ao final do tempo expiratório espontâneo, prosseguindo até o volume residual. (imagens 10 e 11) 

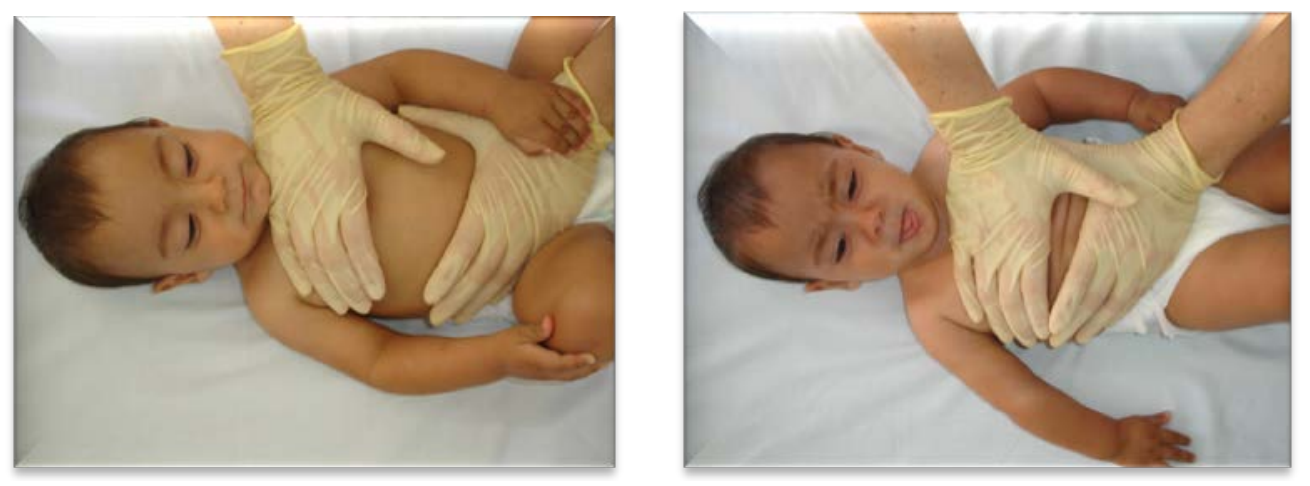

Imagens 10 e 11- arquivo do Setor de Fisioterapia - CAISM-UNICAMP

A aplicação da pressão deve ser lenta, opondo-se a duas ou três tentativas inspiratórias da criança. Nesta técnica, não se exerce pressão durante a primeira parte da expiração. Pode ser associada à vibração manual e/ou à DRR.

Está direcionada a toda situação de obstrução brônquica do lactente, causada por estase de secreção.

Em razão da pressão abdominal exercida ao final do tempo expiratório, a ELPr é contra-indicada em pacientes em pós-operatório de atresia de esôfago, na doença do refluxo gastroesofágico, em malformações cardíacas e afecções neurológicas centrais, ou ainda, em qualquer síndrome abdominal não identificada. Em casos de broncoespasmo, se a técnica for precedida de uma aerossolterapia broncodilatadora, não há contra-indicação.

O local de ação sistemática da ELPr situa-se nas 5 ou 6 primeiras gerações brônquicas do lactente. Entretanto, uma ação ocasional na periferia do aparelho respiratório pode ser observada. (POSTIAUX, 2000; FELTRIM, 2001; POSTIAUX, 2001)

\subsubsection{Drenagem Autógena Assistida (DAA)}

A DAA é uma adaptação da técnica de drenagem autógena (DA) para lactentes ou crianças pequenas. (LANNEFORS, 2004; COPPO, 2007)

Baseada na fisiologia da respiração, utiliza o fluxo expiratório como força ativa para mobilização do muco. A DA, descrita por Chevaillier no final dos anos de 1970, é uma técnica de higiene brônquica ativa, que utiliza inspirações e expirações lentas e controladas pelo paciente. A técnica envolve a utilização de três modos ventilatórios:

- ventilação a baixo volume pulmonar, que objetiva o descolamento de secreções distais; - ventilação a médio volume pulmonar, que visa coletar as secreções localizadas nas vias aéreas de médio calibre; e 
- ventilação a alto volume pulmonar, que promove a eliminação das secreções das vias aéreas proximais. (POSTIAUX, 2000; FELTRIM, 2001)

Na forma passiva (DAA), o paciente é posicionado em decúbito dorsal e uma faixa elástica, colocada entre as últimas costelas e as cristas ilíacas, é utilizada para estabilização do abdome.

Com as mãos envolvendo bilateralmente o tórax da criança, o fisioterapeuta realiza uma pressão suave, aumentando lentamente a velocidade do fluxo expiratório (acompanhando o padrão respiratório da criança), prolongando a expiração até o volume residual. (imagem 12)

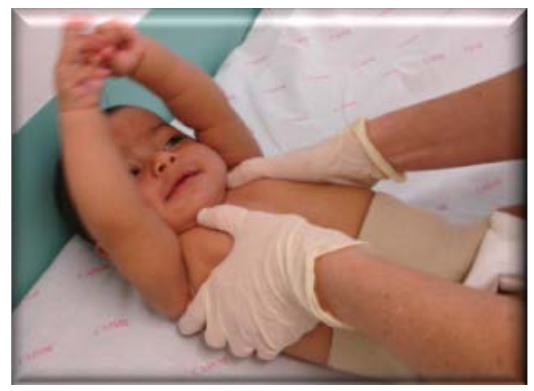

Imagem 12- arquivo do Setor de Fisioterapia - CAISM-UNICAMP

Esta pressão deve ser sustentada até que se perceba o aumento do esforço inspiratório da criança.(imagem 13)

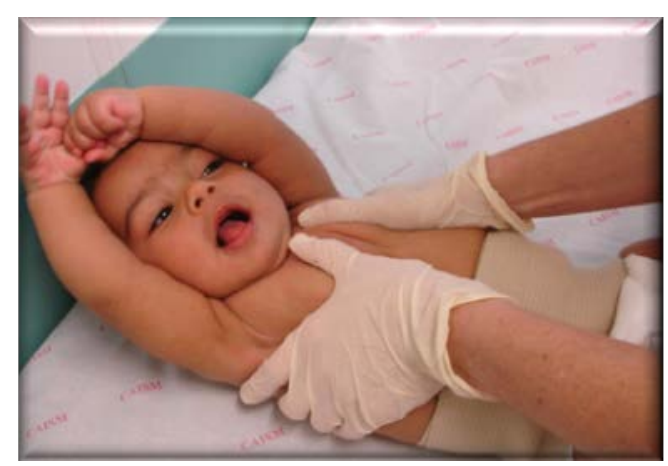

Imagem 13- arquivo do Setor de Fisioterapia - CAISM-UNICAMP

A aplicação de pressão excessiva desencadeará respostas de proteção (bloqueio reflexo torácico de defesa), com o objetivo de resistir à manobra.

Em lactentes atendidos ambulatorialmente, a DAA pode ser combinada ao bouncing, após a aquisição do controle de cabeça. Sentado em uma bola, com a criança sentada em sua perna, o terapeuta posiciona as mãos bilateralmente ao tórax, realizando a pressão como descrito anteriormente. (imagens 14 e 15) 

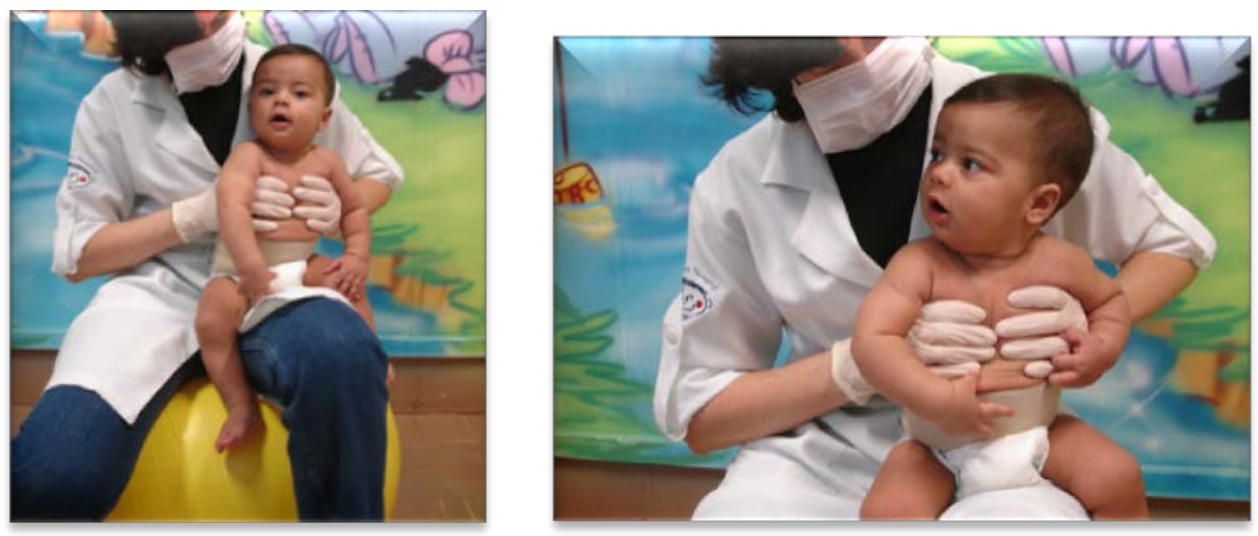

Imagens 14 e 15- arquivo do Setor de Fisioterapia - CAISM-UNICAMP

Ao mesmo tempo, o terapeuta realiza movimentos rítmicos para cima e para baixo, utilizando o deslocamento do próprio corpo. Este movimento provoca alterações na frequência respiratória do paciente, com consequentes variações do volume pulmonar. (LANNEFORS, 2004)

Já em recém nascidos pré termo, a utilização da técnica necessita de modificações baseadas nas limitações impostas pelas características fisiológicas desta faixa etária. A necessidade de se manter estas crianças em incubadoras, dificulta a colocação das mãos no tórax na posição descrita originalmente. Além disso, o apoio abdominal realizado pela cinta, pode provocar alterações do fluxo sanguíneo cerebral. Nestes recém nascidos, utilizamos a fralda para sustentação do abdome e posicionamos a mão torácica entre a fúrcula esternal e a linha intermamária, realizando a técnica da mesma maneira descrita anteriormente. (imagem 16)

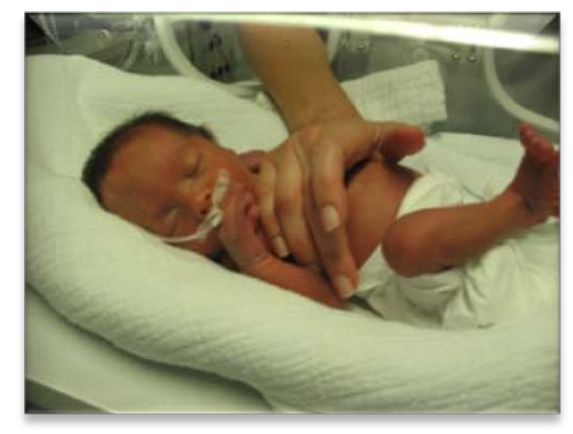

Imagem 16- arquivo do Setor de Fisioterapia - CAISM-UNICAMP

Os objetivos da DAA são prolongar a expiração até o volume residual e aumentar a velocidade do fluxo expiratório, visando melhorar o transporte do muco para vias aéreas de maior calibre. (LANNEFORS, 2004)

Está indicada em casos de obstrução brônquica por estase de secreções, no recémnascido, lactente e na criança incapaz de cooperar. 
Esta técnica não apresenta contra-indicações descritas, portanto, situações específicas devem ser avaliadas.

\subsection{Exercício de Fluxo Inspiratório Controlado (EDIC)}

Esta técnica, descrita por Postiaux na década de 1980, consiste na realização de manobras inspiratórias lentas e profundas executadas com o paciente em decúbito lateral, sendo que, a região a ser tratada deve ser posicionada supralateralmente.

O decúbito lateral explora os efeitos de expansão regional passiva dos espaços aéreos periféricos, obtida pela hiperinsuflação relativa do pulmão supralateral e aumento do diâmetro transversal do tórax.

A seletividade é obtida pelo posicionamento preciso, de acordo com a localização da infecção, ou seja, em caso de acometimento nas regiões posteriores do pulmão, o paciente deve ser posicionado em decúbito lateral, com o corpo ligeiramente rodado para frente e a pélvis perpendicular ao plano da maca. Nos acometimentos em regiões anteriores, o corpo do paciente deve ser ligeiramente rodado para trás, deixando a pélvis perpendicular ao plano de apoio. (POSTIAUX, 2000; FELTRIM, 2001)

O posicionamento em supralateral aumenta o diâmetro torácico transversal no final da inspiração, tendendo a acentuar as forças gravitacionais sobre o parênquima pulmonar.

A utilização de incentivadores inspiratórios pode auxiliar na manutenção de um fluxo inspiratório lento e no controle volume inspirado, por meio de um feedback visual tanto para o terapeuta quanto para o paciente.

Uma apnéia deve ser realizada ao final da inspiração. Do ponto de vista mecânico, esta associação de inspiração lenta e apnéia pós inspiratória tem por objetivo igualar as constantes de tempo das unidades pulmonares periféricas (onde a resistência e a complacência estão alteradas), diminuindo a desigualdade de distribuição da ventilação, melhorando o assincronismo ventilatório. Esta técnica necessita de acompanhamento estetoacústico para perceber a progressão das secreções.

É indicada para pacientes com idade a partir de 3 ou 4 anos, podendo ser iniciada já no estágio agudo de uma afecção, com o objetivo de evitar as complicações decorrentes. A posição adequada será definida por ausculta e/ou Rx.

Fazem parte dos limites e contra-indicações do EDIC, a falta de cooperação do paciente, a dor resultante de um acometimento pleural e a hiper-reatividade brônquica. Esta técnica deve ser absolutamente contra-indicada em pós-operatórios de pneumectomia.

Os exercícios de fluxo inspiratório controlado promovem a insuflação e a depuração do pulmão profundo, região pulmonar onde há elastância dinâmica, ou seja, além da $16^{\mathrm{a}}$ geração brônquica. 
Exercícios de inspiração controlada devem ser incluídos em toda terapia de higiene brônquica, em crianças a partir de 3 ou 4 anos de idade. Além de prevenir as atelectasias frequentes nesta faixa etária, devido à escassa ventilação colateral, estes exercícios são capazes de propiciar o descolamento e o deslocamento de quantidades mais significativas de secreção, quando estas ainda estão localizadas em regiões pulmonares mais periféricas. (POSTIAUX, 2000)

English Title Main airway clearance techniques in pediatrics

\begin{abstract}
The airway clearance techniques used in neonatal and pediatric patients, that are continuously growing and developing, differ substantially of those used in adults. Pediatric techniques need to respect patient's age and physiological and anatomical aspects related, pulmonary and other associated diseases, clinical picture and evolution, cooperation and adherence to treatment, and neuropsychomotor development. We describe respiratory physiotherapy techniques for upper and lower airways clearance.
\end{abstract}

Keywords respiratory physiotherapy, airway clearance, neonate, pediatrics Referências

1- BARTHE, J.; BINOCHE, C.; BROSSARD,V. Pneumokinésithérapie. Paris. Doin Editeurs, 1990.

2- BERNARD-NARBONNE, F.; DAOUD, P.; CASTAING, H.; ROUSSET, A. Efficacité de la kinésithérapie respiratoire chez des enfants intubés ventilés atteints de bronchiolite aiguë. Archives de Pédiatrie, 10: 1043-7, 2003.

3- CONFÉRENCE de Consensus sur la Kinésithérapie Respiratoire . Lyon, 2 et 3 décembre, 1994. Kinésithérapie Scientifique, Paris,nº 344, 45-54, abril 1995.

4- COPPO, M.R.C. ; STOPIGLIA, M.S. Técnicas fisioterapêuticas convencionais e atuais. Capítulo 30. em SARMENTO, GJV; PEIXE, AAF; CARVALHO, FA. Fisioterapia respiratória em pediatria e neonatologia. São Paulo. Ed. Manole, 2007. caps 19 e 30.

5- DELAUNAY, J.-P. Conférence de consensus en kinésithérapie respiratoire. Place respective des différentes techniques non instrumentales de désencombrement bronchique. Paris: Cah. Kinésithér, 1998. 192(4):14-22. 
6- DEMONT, B., VINÇON, C., BAILLEUX, S., CAMBAS, C-H., DEHAN, M., LACAZEMASMONTEIL, T. Chest physiotherapy using the expiratory flow increase procedure in ventilated newborns: a pilot study. Physiotherapy 93: 12-16, 2007.

7- FELTRIM, M. I.; PARREIRA, V. Fisioterapia Respiratória. Consenso de Lyon. 1994 2000. São Paulo, 2001.

8- GÜRSLI, S.; GUPTA, S.; FLORES, A. Physiotherapy all over the world. Physiotherapy in the treatment of cystic fibrosis. (IPG/CF) 3a edição, 2002.

9- LANNEFORS, L.; BUTTON, B. M.; MCLLWAINE, M. Physiotherapy in infants and young children with cystic fibrosis: current practice and future developments. $J$ R Soc Med. 97 (suppl. 44): 8-25, 2004.

10- OBERWALDNER, B. Physiotherapy for airway clearance in paediatrics. Austria:

Eur Respir J. 15:196-204, 2000

11- POSTIAUX, G. Kinésithérapie Respiratoire de L’Enfant. Les téchniques de soins guidées par l’auscultation pulmonaire. Belgique. De Boeck Université, 2000. 2a édition.

12- POSTIAUX, G. Quelles sont les techniques de désencombrement bronchique et des voies aériennes supérieures adaptées chez le nourrisson? Arch Pédiatr; 8 Suppl. 1: 117-25, 2001.

13- POSTIAUX, G; LENS,E. De ladite “Accélération du Flux Expiratoire(AFE)”: où forced is...fast (Expiration Technique-FET)! Ann Kinésithér . 19(8):411-27, 1992.

14- STOPIGLIA, M.S.; COPPO, M.R.C. Doenças obstrutivas de vias aéreas superiores. Capítulo 19. em SARMENTO, GJV; PEIXE, AAF; CARVALHO, FA. Fisioterapia respiratória em pediatria e neonatologia. São Paulo. Ed. Manole, 2007. caps 19 e 30.

15- WILS, J. L'accélération du flux expiratoire chez l'adulte: technique de désencombrement bronchique. Paris: Cah. Kinésithér., 192(4):1-13, 1998. 